Review Article

\title{
Exploiting the mycobacterial cell wall to design improved vaccines against tuberculosis
}

\author{
Matteo Morandi ${ }^{1}$, Michela Sali ${ }^{1}$, Riccardo Manganelli $^{2}$ and Giovanni Delogu ${ }^{1}$ \\ ${ }^{1}$ Istituto di Microbiologia, Università Cattolica del Sacro Cuore, Rome, Italy \\ ${ }^{2}$ Department of Molecular Medicine, University of Padua, Padua, Italy
}

\begin{abstract}
The only vaccine available against tuberculosis (TB), the Bacille Calmette-Guerin (BCG), does not provide effective protection against the most common forms of adult TB and in recent years efforts have been made to develop a new and improved vaccine. Among the strategies implemented, the generation of a new live attenuated mycobacterial strain is seen as one of the most promising and feasible, for scientific, ethical and practical reasons. The new understanding of the biology of the tubercle bacilli and of host-pathogen interaction processes, coupled with the possibility to engineer BCG or M. tuberculosis, opened new avenues to design "intelligent" vaccines, capable of eliciting the immune response associated with protection while avoiding the induction of the host immune response associated with immunopathology. The complex and highly immunogenic mycobacterial cell wall can shape the general and antigen specific immune response elicited following immunization, and the possibility to exploit this knowledge may lead to the development of new vaccines that could help conquer this ancient human disease.
\end{abstract}

Key words: tuberculosis; vaccine; BCG; cell wall; HBHA

J Infect Dev Ctries 2013; 7(3):169-181.

(Received 31 October 2012 - Accepted 31 January 2013)

Copyright (C) 2013 Morandi et al. This is an open-access article distributed under the Creative Commons Attribution License, which permits unrestricted use, distribution, and reproduction in any medium, provided the original work is properly cited.

\section{Introduction}

Among the infectious diseases that afflict mankind, tuberculosis (TB) has the almost unique feature of being one of the most ancient and deadly [1]. The 2011 WHO report quotes estimates of 8.8 million incidence cases worldwide, 1.1 million deaths in the HIV-negative population, and an additional 35 million deaths of HIV-positive subjects [2]. About one million cases involve children, with 130,000 deaths per year in the pediatric population, making TB among the top 10 causes of deaths in childhood. The highest prevalence rates $(>300 / 100 \mathrm{k})$ are found in developing countries, particularly in sub-Saharan Africa, including South Africa, Zimbabwe and Congo, and in Southeast Asia, including Cambodia, Vietnam and the Philippines [2]. However, TB rates have been declining worldwide since 2006, and the target of the "Stop TB partnership" of halving TB mortality by 2015 compared to 1990 may be met. The impact of the introduction of new diagnostic tools in highburden countries, strongly supported by the WHO and other international institutions, on TB epidemics remains to be determined. The emergence of multidrug resistant strains (MDR-TB), extensively resistant strains (XDR-TB) [3] and totally resistant strains (TDR-TB) [4] is raising concerns at the global level and prompted health authorities to strengthen and reinforce control strategies to limit their spread. Even when these ambitious targets are met, the burden of TB at the global level will remain substantial, posing a major threat primarily to the young adult population, and as a result TB will continue to be a major obstacle toward sound economic, social, and political development of the countries where TB is endemic.

\section{Need for a new vaccine}

The Bacille Calmette-Guerin (BCG) vaccine, introduced almost one hundred years ago, is still the only vaccine available and used against TB. BCG has a widely proven safety record and it is certainly one of the most frequently administered vaccines in the world [5]. In countries where $\mathrm{TB}$ is endemic, newborns are immunized with BCG immediately after birth since it protects infants from the most insidious forms of TB, such as disseminated infection and meningeal TB. Nevertheless, the efficacy of $\mathrm{BCG}$ in protecting against the most common forms of adult TB has been challenged by several clinical studies $[6,7]$ and there is 
a common consensus that BCG is unable to provide significant protection against pulmonary $\mathrm{TB}$, which is the only form of $\mathrm{TB}$ that causes transmission of the bacilli [8].

In the last two decades, thanks to a renaissance in TB research, many efforts have been made to develop a new and improved vaccine. Subunit, viral-vectored, DNA-based vaccines have been developed using many different $M$. tuberculosis antigens and tested in preclinical animal models of TB infection. The results obtained varied depending on the vaccine used, though very few experimental vaccines were capable of inducing a protective immune response superior to that induced by BCG [9-12]. Attempts have also been made to obtain attenuated $M$. tuberculosis strains that, while being equally or even less virulent than BCG, could induce improved protection against $M$. tuberculosis infection [13]. In any case, none of these new vaccines was completely protective and capable of preventing infection. These results, coupled with the fact that BCG is effective in preventing the most severe forms of $\mathrm{TB}$ disease in infants, make the substitution of BCG with a new vaccine not feasible for ethical concerns [14]. For these reasons, an option that is being pursued aims to develop an improved version of BCG which could be administered in substitution of the currently available strain. The most common strategy has been that of engineering BCG to express selected M. tuberculosis antigens [15] or other heterologous proteins that would improve immunogenicity and enhance the protective activity against TB. Some of these recombinant strains have successfully passed preclinical testing and evaluation in human clinical trials has been started.

\section{Live attenuated mycobacterial strains}

Since it is widely accepted that, for ethical reasons, BCG immunization of infants cannot be discontinued, many efforts have been made to develop improved live and attenuated mycobacterial strains capable of inducing enhanced and long-lasting immunity against M. tuberculosis. Several groups have attempted to develop new attenuated strains by inactivating one or more selected genes in $M$. tuberculosis to obtain a safe vaccine capable of expressing all $M$. tuberculosis antigens. Many strains have been obtained and tested and the results of preclinical studies have been promising in some cases, with enhanced protective activity of some of these vaccines compared to BCG [16]. Some of the recently developed live-attenuated M. tuberculosis strains are reported in Table 1. Among the most advanced $M$. tuberculosis attenuated vaccine is the phoP M. tuberculosis mutant (SO2) developed by Carlos Martin's group, which demonstrated better protection and safety than BCG [17] and was further attenuated by deleting the gene encoding virulence factor fadD26 [18], obtaining the attenuated $M$. tuberculosis strain MTBVAC01. However, even if promising in terms of protection against $M$. tuberculosis infection, live-attenuated M. tuberculosis strains must fulfill stricter safety issues than other vaccines and obtaining approval for them could take a long time. On these premises, immunization with BCG remains the path of choice.

\section{Recombinant BCG}

Another option to develop an improved live attenuated vaccine is to engineer the current vaccine BCG to improve its protective activity. In the last two decades many attempts have been made and human clinical trials have been initiated for three of the recombinant BCG strains developed: rBCG30, VPM1002 and AERAS-422. rBCG30 is a recombinant BCG expressing one of the most actively secreted antigens of $M$. tuberculosis, Ag85B, in a five-fold amount compared to that expressed by the wild type strain [15], and results of the phase I clinical trial have already been reported [19]. The rBCG30 was shown to induce enhanced protection in animal models compared to the parental strain while maintaining a good safety record [20]. Another rBCG strain in an advanced stage of development is the VPM1002, which is a BCG recombinant strain that has been engineered to express listeriolysin $\mathrm{O}$ (LLO) from Listeria monocytogenes. In VPM1002, LLO is expressed in fusion with the $\mathrm{N}$-terminal region of $\mathrm{Ag} 85 \mathrm{~B}$, under the control of the hsp60 promoter, and this cassette was inserted so to replace the ureC gene of M. tuberculosis [21,22]. VPM1002 induced better protection over parental $\mathrm{BCG}$, and this effect was related to its ability to stimulate broader and different $\mathrm{T}$ cell populations involved in protective immunity [23]. Now that its safety has been proven (www.clinicaltrials.gov, ID\# NCT01113281 and NCT00749034), VPM1002 is currently undergoing phase IIa trials to assess its immunogenicity and safety in the target population [24]. Lastly, the AERAS-422 vaccine, which basically combines concepts underlying VPM1002 and rBCG30 [25], was shown to induce effective protection in preclinical animal models; however, though the phase I clinical trial was stopped because of an adverse effect observed in two participants (www.clinicaltrials.gov ID\# NCT01340820). 
Table. List of M. tuberculosis components that have been used to exploit the mycobacterial cell wall to modulate the host immune response elicited in a vaccine setting

\begin{tabular}{lll}
\hline COMPONENT & \multicolumn{1}{c}{ FUNCTION } & \multicolumn{1}{c}{ EMPLOYMENT } \\
\hline & & \\
& Apoptosis induction [38] & Expression in saprophytic mycobacteria \\
& Downregulation of IFN- $\gamma \quad$ induced & {$[40]$} \\
& MHCII expression [36] & Deletion in BCG [41] \\
& M $\Phi$ apoptosis [37] & Deletion in H37Rv [42] \\
\hline
\end{tabular}

HBHA

\section{ESX secretion systems}

Bacterial agglutination [45; 46]

Dissemination from the primary site of infection [45]

ESX-1: Secretion of ESAT-6 and CFP-
Protection in the mouse model of TB [55]

Diagnostic marker in QFT-test [59] 10 which are employed in IGRAs to diagnose TB infection [71]

Encoded by the RD1 region which loss is the main molecular mechanism of attenuation of BCG [69]

ESX-3: Essential for growth and viability in MTb [79]

Growth in iron-deprived environment [78]

ESX-5: Modulates $М \Phi$ response ( $M$. marinum) [82]
ESX-1: H37Rv $\Delta R D 1$ protects mice against MTb infection similarly to BCG [72]

Its deletion is one of the main causes of BCG attenuation [70]

ESX-3: IKEPLUS $M$. smegmatis is susceptible to immune killing and stimulates the clearance of $M$. tuberculosis in infected mice [81]

ESX-5: its disruption in Mtb causes loss of PPE protein secretion, changes in cell wall integrity, strong attenuation and protection similar to BCG [66]

\section{PhoP}

H37Rv $\Delta$ phoP shows reduced growth in vitro, is impaired in replication in ВMM $\Phi$ and in mice [74]

Involved in the biosynthesis of lipids [75]

Functionally linked with ESX-1 system [73]
$\mathrm{SO} 2$ mutant is more attenuated than BCG, eliciting high protection in mice and superior protection in guinea pigs [17]

SO2 mutant is safe once used as liveattenuated vaccine against TB [77]

\section{SigE}

As ECF, is involved in response to surface stress such as heat-shock, SDS [85]

Its depletion in $\mathrm{H} 37 \mathrm{Rv}$ results in attenuation in $Н M \Phi$ and $M M \Phi$, and is more sensitive to killing in the latter[85]

\section{PE delivery system}

PE domain of PE_PGRS33 delivers proteins to the mycobacterial surface $[95,96]$
$\operatorname{Sig} E$ null mutant is unable to grow in THP1-M $\Phi$ and severely attenuated in mice $[85,86]$

SigE mutant elicits stronger immune response (IFN- $\gamma$ and TNF- $\alpha$ ) and improved protection than BCG in mouse model of TB once administered as liverecombinant vaccine [87]

Fusion of antigens with the PE domain results in the expression of the latter on the surface [96] which can result in higher immunogenicity and protective activity when employed for $\mathrm{rBCG}$ engineering [99] 


\section{Exploiting the mycobacterial surface}

M. tuberculosis is an elusive pathogen and as such is an active manipulator of the host immune system, exploiting a large arsenal of biomolecules which allows the bacilli to interact with a wide array of immune ligands [26,27]. Most of these biomolecules are localized in the complex mycobacterial cell wall, which has a very peculiar composition known to play a pivotal role in the pathogenesis of mycobacterial infections. The main components of the mycobacterial cell wall are lipoarabinomann, arabinogalactan and other sugars; mycolic acids; glycolipids and phenolic lipids; and peptidoglycan. It is well-established that the mycobacterial cell wall is a very immunogenic component with strong immunostimulatory properties as classically highlighted by the use of the Freund's adjuvant, which is made of oleic acid and heat-killed M. tuberculosis. The adjuvant properties are linked to the pro-inflammatory activity of these molecules that induce TNF, IL-6, IL-1, IL-12, and trigger upregulation of MHC-II and CD1d1 on macrophages [28]. Not surprisingly, some of the most immunogenic antigens of $M$. tuberculosis are localized on the cell wall or are actively secreted, using specialized secretion systems apparatus such as the type seven secretion system (T7SS) [29,30]. The elucidation at the molecular level of the mycobacterial cell wall components is shedding some light on the mechanisms implemented by the tubercle bacilli to subvert and manipulate the host immune response. This information could be instrumental in designing new and innovative strategies aimed at engineering BCG or M. tuberculosis wild type strains to develop a new vaccine with enhanced protective activity against TB. The main cell wall components of M. tuberculosis that can be exploited to design new live attenuated vaccines against TB are shown in the Figure.

\section{9-kDa protein}

The relevance of lipoproteins in bacterial physiology and their potential for serving as virulence factors led many researchers to focus on such bacterial components. Many of the lipoproteins have been found to be targets of both the innate and acquired immune responses, and they represent a significant class of cell envelope proteins involved in interactions between the organism and the host [31]. Among such proteins, one of the most extensively studied is the 19$\mathrm{kDa}$ antigen encoded by the $R v 3763$ gene in $M$. tuberculosis H37Rv [32]. The 19-kDa glycolipoprotein is abundantly expressed in $M$. tuberculosis, where it is secreted or found in association with the cell wall. As seen in other mycobacterial antigens such as HBHA, post translational modifications have a great impact on the immune response elicited by the $19-\mathrm{kDa}$ protein, since a considerable role for acylation and $O$-glycosilation on the cellular localization and the immune response associated with this antigen have been established [33]. Originally, this glycolipoprotein raised the interest of the scientific community because it was demonstrated that murine antibodies recognized it as a major antigen on crude $M$. tuberculosis extracts; furthermore, other homologues proteins were found in other pathogenic mycobacteria including Mycobacterium avium, Mycobacterium intracellulare and Mycobacterium leprae [34], suggesting the putative role of $19-\mathrm{kDa}$ as a virulence factor. Many insights were offered for the pleiotropic role of the 19$\mathrm{kDa}$ protein in modulating the innate immune response, such as the induction of cytokine genes [35] and the downregulation of IFN- $\gamma$ induced MHC Class II expression [36]. However, it is now considered an active player in the mechanisms of subversion of the immune system by $M$. tuberculosis, since it induces apoptosis in macrophages through a TLR-2 pathway $[37,38]$. The finding that the $19-\mathrm{kDa}$ protein is heavily involved in the induction of apoptosis led to idea that it could be possible to enhance vaccine-induced immunity by using pro-apoptotic vaccines, which may be a way to generate a more effective immune response without employing subunit or killed vaccines [39]. However, the expression of the 19-kDa protein in saprophytic mycobacteria employed as vaccines against tuberculosis showed a detrimental effect on the protection against the tubercle bacilli [40]. Inactivation of the Rv3763 gene in BCG resulted in a vaccine strain with a similar protective activity compared to the wild type BCG against $M$. tuberculosis infection [41]. On the other hand, inactivation of Rv3763 in $M$. tuberculosis $\mathrm{H} 37 \mathrm{Rv}$ resulted in an attenuated strain capable of inducing some protective activity which was, unfortunately, no different compared to that induced by BCG [42].

Taken together, these data suggest that the highly immunogenic $19-\mathrm{kDa}$ protein has a central role in $M$. tuberculosis pathogenicity, functioning to mislead the host immune system. Nevertheless, 19-kDa cannot be considered a potential candidate antigen for the development of a new vaccine against TB, since the immune response triggered is detrimental to the ability of the host to control M. tuberculosis infection. The pro-apoptotic activity seen in the $19-\mathrm{kDa}$ protein could fall within the immune subversion mechanisms 
Figure 1: Factors heavily involved in the regulation and the composition of the cell wall of M. tuberculosis

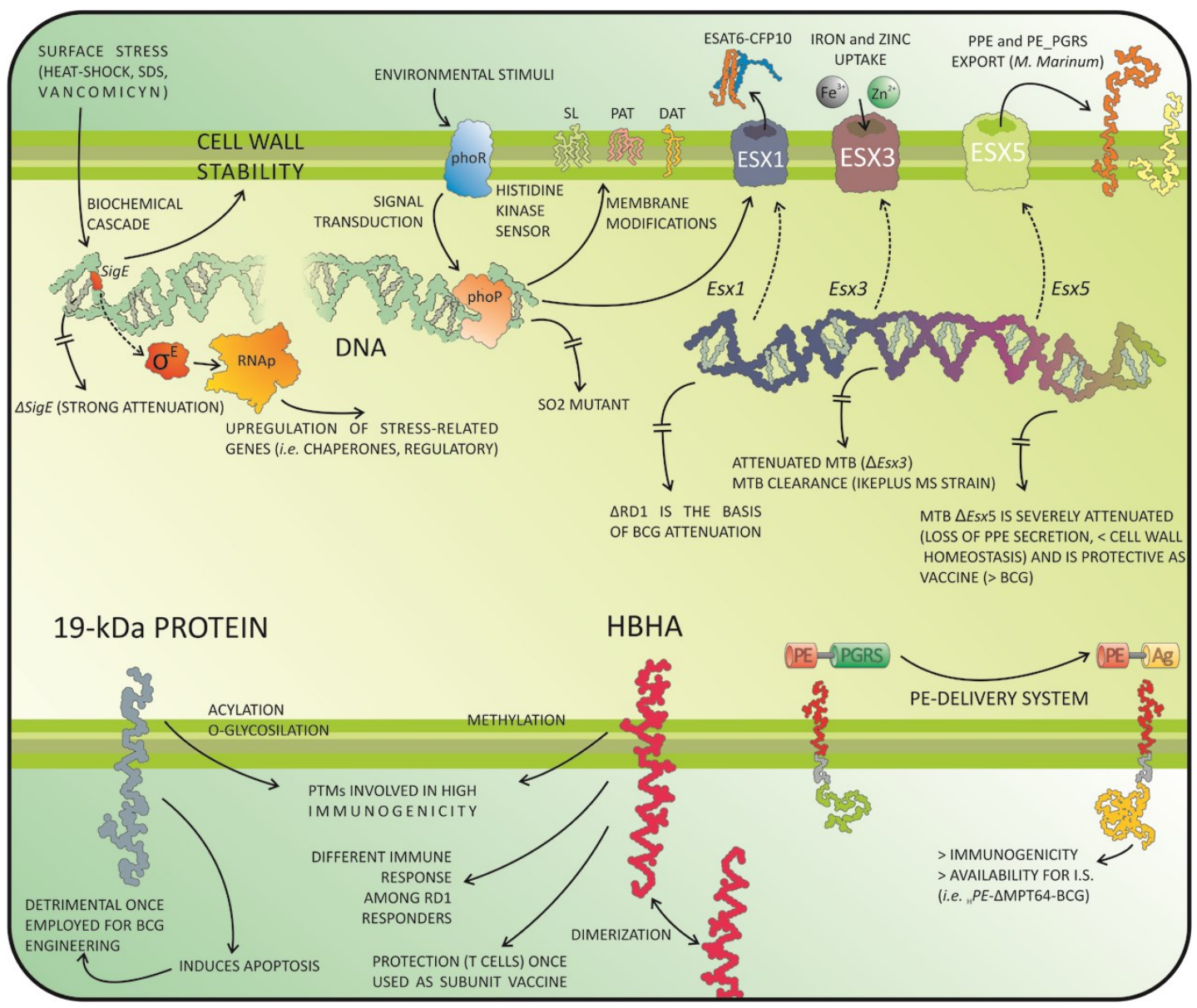

SigE (upper left) is activated in response to surface stresses through a biochemical pathway, promoting the transcription of stress response genes once associated to the RNAp, and the regulation of the cell wall stability. SigE is tightly associated with the immune response, as highlighted by the disruption of the gene in M. tuberculosis ( $\triangle S i g E$ mutant), which leads to a strong attenuation of the mutant while maintaining the ability to elicit a robust immune host response.

The PhoPR regulation system (upper center) has a central role in M. tuberculosis virulence, as highlighted by the $\mathrm{SO} 2$ mutant severe attenuation. PhoPR is activated in response to environmental stimuli; PhoP modulates the composition of the mycomembrane through the regulation of the biosynthesis of lipids such as SL, PAT and DAT; PhoP is also involved in the regulation of the ESX1 system.

The T7SS of M. tuberculosis (upper right): ESX1 is encoded by the RD1 region of M. tuberculosis: the deletion of RD1 is accountable for the attenuation of BCG. ESX1 is responsible for the secretion of highly immunogenic proteins such as ESAT6 and CFP10. ESX3 is involved in $\mathrm{Fe}^{3+}$ and $\mathrm{Zn}^{2+}$ uptake and is a central virulence factor in $M$. tuberculosis; recombinant $M$. smegmatis equipped with esx3 (IKEPLUS strain) stimulates M. tuberculosis killing and acts as sterilizing vaccine. ESX5 is heavily involved in cell wall homeostasis and composition, and its abrogation in the $\Delta E s \times 5$ strain causes attenuation in $M$. tuberculosis similar to the one observed with BCG.

Differences between two surface-exposed and highly immunogenic antigens (lower left): The 19-kDa protein and HBHA of M. tuberculosis. Even if both the antigens are prone to post-transcriptional modifications, which are highly involved in their immunogenicity, their employment as vaccines leads to opposite results. The 19-kDa glycolipoprotein, even if proapoptotic and immunogenic, shows a detrimental effect once used for engineering recombinant BCGs. On the other hand, HBHA, which is highly immunogenic, evokes a strong T-cell response, giving notable protection once used as protein vaccine in the mouse model of TB.

The PE-delivery system (lower right): The PE domain of PE_PGR33 contains sufficient information to deliver the protein to the surface, and it was shown that a fusion between the PE domain and another antigen (i.e. ${ }_{\mathrm{H}} P E-\triangle \mathrm{MPT} 64-\mathrm{BCG}$ ) results in the exposition of the latter on the mycobacterial surface, which results in an improved availability for the immune system and, consequently, a major immunogenicity. For further explanations and references, see text.

Abbreviations: DAT, diacyltrehaloses; PAT, polyacyltrehaloses; SL, sulfolipids; RNAp, RNA-polymerase; PTMs, posttranscriptional modifications; IS, immune system 
operated by the tubercle bacilli, as it has been shown that early apoptosis tends to favor the parasite survival rather than its killing [43]. While the paradigm given by such a protein could be exploited for the development of recombinant vaccines against pathogenic microorganisms other than $M$. tuberculosis, its use for the development of a vaccine against TB appears not feasible. Overall, the results obtained with the $19-\mathrm{kDa}$ protein underscore the implication that an antigen associated with the mycobacterial cell wall can have in the development of an immune response against $M$. tuberculosis.

\section{$H B H A$}

Heparin-binding haemagglutinin (HBHA) is a 21 $\mathrm{kDa}$ surface exposed protein which has been involved in the mechanism of TB pathogenesis [44]. HBHA mediates adhesion of the bacilli to epithelial cells but not macrophages and is involved in the dissemination of M. tuberculosis from the site of primary infection $[44,45]$. The molecular characterization of HBHA sheds light on the structure-function relationship and their impact on the mechanism of pathogenesis [4649], and the information gathered could open new avenues for the development of innovative prophylactic and therapeutic strategies against TB.

The first attempts to exploit this knowledge aimed at inducing antibodies directed against HBHA that could somehow neutralize the binding of the $M$. tuberculosis bacilli to epithelial cells, to prevent bacterial dissemination. Interestingly, opsonization of BCG with a monoclonal antibody against HBHA was capable of reducing bacterial dissemination from the lung to the spleen [45]. Indeed, several studies showed that HBHA is properly exposed on the surface and that antibodies could bind and potentially neutralize its adhesion properties [50]. However, when antibodies were induced in mice following immunization with a DNA vaccine encoding HBHA, no protection could be observed [51], though the protein expressed by DNA vaccines lacked the proper methylation of the lysines present at C-terminus, which are known to play an important role for the immunological properties of HBHA [46,52,53]. Moreover, protective activity of an HBHA-based vaccine correlated with the ability to elicit HBHAspecific $\mathrm{T}$ cells secreting IFN- $\gamma$ but not with the ability to induce antibodies $[54,55]$. Hence the results so far observed in preclinical models of TB do not support the hypothesis that antibodies against the surface exposed adhesion HBHA could exert a protective effect against $M$. tuberculosis infection or TB disease.
The correlation of the HBHA-induced protective activity with a strong $\mathrm{T}$-cell response in mice correlated with another major feature of HBHA. In fact, PBMCs from subjects with latent TB infection, but not patients with active TB, are capable of secreting IFN- $\gamma$ when stimulated ex vivo with HBHA; conversely, patients with active $\mathrm{TB}$, but not subjects with latent infection, show antibodies in the sera specific for HBHA [52-54]. These results imply that during $M$. tuberculosis infection the host-specific immune response directed against HBHA differs depending on the clinical status. These findings are relevant from a diagnostic point of view, since it would be possible to discriminate patients with active TB from those infected but with no overt sign of the disease [56-61]. At the same time, these differential immune responses in TB patients versus healthy TBinfected subjects may suggest that an effective $\mathrm{T}$ cell response against HBHA could help to control $M$. tuberculosis replication and prevent disease development [54,62]. Interestingly, promising results were obtained in preclinical animal models, where immunization with HBHA was capable of eliciting levels of protective activity similar to those induced by BCG [54,55]; other studies provided further support of the role of HBHA as a candidate vaccine against TB $[63,64]$. Interestingly, it was found that intranasal immunization of mice with HBHA adjuvated with the cholera toxin induced an effective humoral and cellular immune response, and protection was measured as a reduction of the bacilli dissemination from the lung to the spleen [63]. These results highlight the potential relevance of mucosal administration of an HBHA-based vaccine and suggest that relevant animal models specifically investigating the dissemination of the bacilli from the site of primary infection should be used, which is known to be a primary step in human TB pathogenesis [65]. It would be interesting to investigate the activity of an HBHA-based vaccine in the guinea pig or rabbit model of $\mathrm{TB}$, and monitor vaccine efficacy by specifically measuring the number of secondary lesions occurring in later stages of infection.

These observations clearly underscore the importance of the host immune response against a mycobacterial cell surface antigen on the clinical status of $\mathrm{TB}$, and highlight that this host immune response could be affected by yet uncharacterized events whose understanding could lead to improved strategies to control TB. 


\section{ESX T7SS}

The identification of T7SS in mycobacteria [29] provided a new understanding of the molecular mechanisms associated with protein secretion and their impact on TB pathogenesis. In $M$. tuberculosis five ESX secretion systems have been identified (Esx1-5) and their characterization is opening new avenues of inquiry on the complex host-pathogen interactions between M. tuberculosis and its host [66,66-68].

ESX-1

The best characterized T7SS in M. tuberculosis is ESX-1, which is encoded in the region of difference 1 (RD1) and its deletion is responsible for the attenuation of the vaccine strain BCG $[69,70]$. ESX-1 encodes for a complex protein machinery that warrants the secretion, among other proteins, of Esat-6 and CFP-10 proteins (EsxA and EsxB), which are the two highly immunogenic proteins used in the IGRAs assays to diagnose TB latent infection [71]. Complementation of the BCG strain with a cosmid containing the RD1 genomic region restored EsxA/B secretion and resulted in a more virulent BCG strain, clearly showing that the deletion of ESX-1 is the major molecular mechanism of attenuation of BCG $[69,72]$. The importance of the role of ESX-1 in virulence was also indirectly demonstrated by showing that the main mechanism of attenuation of the avirulent M. tuberculosis strain H37Ra consists in a point mutation of the phoP gene, which abrogates secretion of Esat-6 [73]. Previous studies have shown that inactivation of phoP, which encodes the transcriptional regulator of the two-component system PhoPR, causes attenuation of the virulent $M$. tuberculosis H37Rv strain [74], and when this attenuated strain was used as a vaccine, the levels of protective activity induced were higher compared to those afforded by BCG [17]. PhoP controls the synthesis of complex mycobacterial lipids which exhibit immunomodulatory properties; in addition to abrogating the secretion of Esat-6, inactivation of phoP in the $M$. tuberculosis $\mathrm{SO} 2$ strain results in significant changes in the mycobacterial cell wall composition [75,76]. As of today, the M. tuberculosis $\mathrm{SO} 2$ attenuated strain is one of the new $\mathrm{TB}$ vaccines in the most advanced stage of development and the results obtained so far are promising [77].

ESX-3

The ESX-3 secretion system is involved in iron uptake in Mycobacterium smegmatis [78] and iron and zinc uptake in $M$. tuberculosis $[79,80]$. While the role of ESX-3 in iron uptake was hypothesized to be related to the import of iron-loaded mycobactin [78], the mechanism by which ESX-3 is involved in zinc uptake is still unknown. Interestingly ESX-3 is essential in M. tuberculosis, but not in M. smegmatis, where a second siderophore (exochelin) can complement the absence of iron-loaded mycobactin uptake [78,79].

High-dose intravenous infection of mice with $M$. smegmatis results in early death of the animals unless the esx-3 region is deleted. In this case, the mutant (designed IKE, for Immune Killing Evasion) is controlled and cleared by a MyD88-dependent bactericidal immune response. When this mutant was complemented with a cosmid encoding $M$. tuberculosis ESX-3 (IKEPLUS), it remained susceptible to innate immune killing, but was able to stimulate bactericidal immunity against virulent $M$. tuberculosis dependent on CD4+ memory T cells [81], making this strain a powerful candidate for the development of novel, sterilizing vaccines.

\section{$E S X-5$}

ESX-5 secretion is the most recently evolved T7SS in mycobacteria and it has been identified in MTB complex, Mycobacterium marinum, and Mycobacterium ulcerans [67]. Its role in virulence has been demonstrated in M. marinum [82] and in $M$. tuberculosis by inactivating one or more parts of the genes' the locus [66]. Disruption of ESX-5 in $M$. tuberculosis resulted in the loss of PPE protein secretion, changes in cell wall integrity and strong attenuation [66], clearly indicating the impact of this system on cell wall homeostasis. Interestingly, the $M$. tuberculosis ESX-5 mutant strains showed protective activity superior to that induced by BCG when administered as a vaccine in a mouse model of $\mathrm{TB}$ [66] [83].

\section{SigE mutant}

Sigma factors are proteins that reversibly associate with RNA polymerase (RNAp) to form the RNAp holoenzyme, providing the promoter recognition function. Bacterial genomes encode a variable number of sigma factors. SigE is one of the 13 sigma factors encoded in the genome of M. tuberculosis [84]. Its transcription is activated in response to several environmental stresses; a sigE null mutant is unable to grow in THP-1-derived macrophages and is severely attenuated in mice $[85,86]$. Interestingly, despite low bacterial burden, $\operatorname{sig} E$ mutant-infected mice produce high levels of protective factors as interferon gamma, 
tumor necrosis factor alpha, inducible nitric oxide synthase and beta defensins in the lungs, suggesting that SigE function confers the ability to avoid the induction of the host response. Since SigE is involved in the regulation of functions responsible for controlling surface stability and composition, it is possible to hypothesize that the enhanced immune stimulation evoked by this strain might be due to the lack of some immunomodulatory molecule on its surface. When the sigE mutant was used to vaccinate mice, it showed protective activity superior to that induced by $\mathrm{BCG}$, and this was particularly evident when mice were challenged with a hypervirulent Beijing strain [87].

\section{PE delivery systems}

The PE and PPE protein families of $M$. tuberculosis include more than 169 proteins whose roles and functions remain elusive [32]. The PE proteins are characterized by a highly conserved Nterminal of $\cong 100$ aa that includes a conserved motif at position 7-8 of proline (P) and glutamic acid (E) which gives the name to the family (PE) [88]. PE proteins are subdivided into three subfamilies: the PE only, which are usually 100 aa or less long and are often coexpressed with a PPE protein to form a heterodimer $[89,90]$; the PE unique, where the PE domain is fused at the $\mathrm{C}$-terminus with a unique domain, that at least for some proteins has enzymatic activity, such as for LipY [91,92]; the PE_PGRS proteins, where the PE domain is followed at the C-terminus by the PGRS domain which contains the typical repetitive motifs of gly-gly-ala, gly-gly-N, which varies in size and sequence and that are unique for each protein. The PE and PGRS domains are linked by a highly conserved domain, which functions as a linker between the PE and PGRS domains. PE_PGRS proteins are exposed at the mycobacterial surface [93,94], and it has been shown that the PE domain of PE_PGRS33 contains sufficient information to deliver the protein on the surface [95,96]. Indeed, fusion of a heterologous protein such as MPT64 or GFP to the PE domain results in the exposure of this protein on the surface [96], clearly indicating that the PE domain could function as a surface delivery system in mycobacteria, though the PE itself is not available on the surface. Indeed, recent data confirmed that the PE-delivery system was efficient in different mycobacterial species such as $M$. smegmatis, M. marinum, M. bovis BCG and $M$. tuberculosis, and that mutations in the $\mathrm{PE}$ domain affected the ability of the PE protein to work as a delivery system [96]. These findings suggest that the PE domain may bring the protein to the mycobacterial outer membrane so that the heterologous antigens localize on the outer part and the linker domain remains embedded on the mycomembrane [97,98].

Expression of a heterologous antigen in the context of the highly immunogenic mycobacterial outer membrane would result in enhanced immunogenicity [96]. When the M. tuberculosis antigen MPT64, which is naturally secreted by $M$. tuberculosis, was over-expressed as a fusion protein with PE in BCG, significant enhanced protective activity was measured in the mouse model of TB [99]. Interestingly, the enhanced activity of the rBCG was observed only when the MPT64 was over-expressed as a fusion protein with the $\mathrm{PE}$, but not when the same protein was over-expressed to localize in the cytoplasm. Indeed, protein localization was able to affect the quality and intensity of the MPT64-specific immune response induced in vivo in the mouse model, and protection correlated with the ability of ${ }_{\mathrm{H}} P E$-_MPT64BCG (the rBCG strain overexpressing the PE_MPT64 fusion protein), but not of the other $\mathrm{rBCG}$ expressing MPT64, to induce specific $\mathrm{T}$ cell clones as determined by spectratyping [99]. These results underscore the relevance that antigen localization has on the type of immune response elicited. It would be interesting to investigate whether similar results will be obtained when other $M$. tuberculosis antigens, which are candidate vaccines against $\mathrm{TB}$, are delivered as a PE fusion. The potential of using the PE delivery system to express antigens of other microorganism to generate a BCG vaccines against other infectious diseases would also be worthy of investigation.

\section{Vaccination strategies based on live attenuated mycobacterial strains}

The preliminary results obtained in preclinical studies using these new recombinant BCG and some of the M. tuberculosis attenuated strains are overall promising and while their activity in human clinical trials remains to be determined, their potential usefulness for implementing vaccination strategies in humans that could result in enhanced protection is worth mentioning. More specifically, the $\mathrm{rBCG}$ strains were engineered to enhance the immunogenicity of one or more specific $M$. tuberculosis antigens selected as valid vaccine candidates against TB, and as such these candidate antigens were shown to induce partial protection when administered as subunit vaccines or as viral-vectored or naked DNA vaccines. Since it has been suggested 
that a main limitation of BCG vaccination is its inability to induce long-lasting immunity against TB, prime-boost vaccination strategies based on BCG priming and heterologous boosting with one or more subunit vaccines have been proposed as valid options to induce a sustained immune response capable of controlling $M$. tuberculosis infection [100]. In this regard the possibility of designing specific homologous prime-boosting strategies, where priming consists of immunization with one of the rBCG strains capable of eliciting a potentiated immune response against a specific antigen, such as $19-\mathrm{kDa}$ protein, MPT64 or HBHA, and a boosting with a vaccine specifically targeting the same antigen, may result in anti-mycobacterial immunity maintained at levels sufficiently high to control $M$. tuberculosis replication in vivo.

The complex mycobacterial cell wall can affect the host-specific immune response against specific $M$. tuberculosis antigens, which could result in enhanced ability to control infection or cause a detrimental effect for the host. Understanding the immunological mechanism regulating the interaction between mycobacterial cell wall components and host immune responses may lead to the generation of recombinant BCG or $M$. tuberculosis attenuated strains with improved protective activity against $\mathrm{TB}$, specifically designed to be included in prime-boost immunization strategies against $\mathrm{TB}$, which may guide our ability to control this ancient human scourge.

\section{Acknowledgements}

This review was written in honor of Professor Giovanni Fadda, who retired from the Academy in 2011, in recognition of his outstanding contribution to microbiology and to the study of tuberculosis.

This work was supported by PRIN grant from the Ministry of Education and Research (MIUR) Nr. 70103566 (MS).

\section{References}

1. Gagneux S (2012) Host-pathogen coevolution in human tuberculosis. Philos Trans R Soc Lond B Biol Sci 367: 850859.

2. World Health Organization (2011) Global Tuberculosis Control. Surveillance, Planning, Financing. (www.who.int/tb/publications/global_report/en/).

3. Cegielski JP (2010) Extensively drug-resistant tuberculosis: "there must be some kind of way out of here". Clin Infect Dis 50 Suppl 3: S195-S200.

4. Udwadia ZF, Amale RA, Ajbani KK, Rodrigues C (2012) Totally drug-resistant tuberculosis in India. Clin Infect Dis 54: 579-581.

5. Brennan MJ, Fruth U, Milstien J, Tiernan R, de Andrade NS, Chocarro L (2007) Development of new tuberculosis vaccines: a global perspective on regulatory issues. PLoS Med 4: e252.

6. Fine PE (1995) Variation in protection by BCG: implications of and for heterologous immunity. Lancet 346: 1339-1345.

7. Colditz GA, Berkey CS, Mosteller F, Brewer TF, Wilson ME, Burdick E, and Fineberg HV (1995) The efficacy of bacillus Calmette-Guerin vaccination of newborns and infants in the prevention of tuberculosis: meta-analyses of the published literature. Pediatrics 96: 29-35.

8. Kaufmann SH (2010) Future vaccination strategies against tuberculosis: thinking outside the box. Immunity 33: 567-577.

9. Sali M, Clarizio S, Pusceddu C, Zumbo A, Pecorini G, Rocca S, Zanetti S, Delogu G, and Fadda G (2008) Evaluation of the anti-tuberculosis activity generated by different multigene DNA vaccine constructs. Microbes Infect 10: 605-612.

10. Weinrich Olsen A, van Pinxteren LA, Meng OL, Birk RP, and Andersen P (2001) Protection of mice with a tuberculosis subunit vaccine based on a fusion protein of antigen $85 \mathrm{~b}$ and esat-6. Infect Immun 69: 2773-2778.

11. Aagaard C, Hoang $\mathrm{T}$, Dietrich J, Cardona PJ, Izzo A, Dolganov G, Schoolnik GK, Cassidy JP, Billeskov R, and Andersen P (2011) A multistage tuberculosis vaccine that confers efficient protection before and after exposure. Nat Med 17: 189-194.

12. Hinchey J, Lee S, Jeon BY, Basaraba RJ, Venkataswamy MM, Chen B, Chan J, Braunstein M, Orme IM, Derrick SC, Morris SL, Jacobs WR Jr, Porcelli SA (2007) Enhanced priming of adaptive immunity by a proapoptotic mutant of Mycobacterium tuberculosis. J Clin Invest 117: 2279-2288.

13. Sambandamurthy VK and Jacobs WR, Jr (2005) Live attenuated mutants of Mycobacterium tuberculosis as candidate vaccines against tuberculosis. Microbes Infect 7: 955-961.

14. Brennan MJ (2005) The tuberculosis vaccine challenge. Tuberculosis (Edinb.) 85: 7-12.

15. Horwitz MA, Harth G, Dillon BJ, and Maslesa-Galic' S (2000) Recombinant bacillus calmette-guerin (BCG) vaccines expressing the Mycobacterium tuberculosis $30-\mathrm{kDa}$ major secretory protein induce greater protective immunity against tuberculosis than conventional BCG vaccines in a highly susceptible animal model. Proc Natl Acad Sci USA 97: 13853-13858.

16. Hondalus MK, Bardarov S, Russell R, Chan J, Jacobs WR, Jr, and Bloom BR (2000) Attenuation of and protection induced by a leucine auxotroph of mycobacterium tuberculosis [In Process Citation]. Infect Immun 68: 2888-2898.

17. Martin C, Williams A, Hernandez-Pando R, Cardona PJ, Gormley E, Bordat Y, Soto CY, Clark SO, Hatch GJ, Aguilar D, Ausina V, Gicquel B (2006) The live Mycobacterium tuberculosis phoP mutant strain is more attenuated than BCG and confers protective immunity against tuberculosis in mice and guinea pigs. Vaccine 24: 3408-3419.

18. Gioffre A, Infante E, Aguilar D, Santangelo MP, Klepp L, Amadio A, Meikle V, Etchechoury I, Romano MI, Cataldi A, Hernàndez RP, Bigi F (2005) Mutation in mce operons attenuates Mycobacterium tuberculosis virulence. Microbes Infect 7: 325-334.

19. Hoft DF, Blazevic A, Abate G, Hanekom WA, Kaplan G, Soler JH, Weichold F, Geiter L, Sadoff JC, and Horwitz MA (2008) A new recombinant bacille Calmette-Guerin vaccine safely induces significantly enhanced tuberculosis-specific immunity in human volunteers. J Infect Dis 198: 1491-1501. 
20. Horwitz MA and Harth G (2003) A new vaccine against tuberculosis affords greater survival after challenge than the current vaccine in the guinea pig model of pulmonary tuberculosis. Infect Immun 71: 1672-1679.

21. Hess J, Miko D, Catic A, Lehmensiek V, Russell DG, and Kaufmann SH (1998) Mycobacterium bovis Bacille CalmetteGuerin strains secreting listeriolysin of Listeria monocytogenes. Proc Natl Acad Sci USA 95: 5299-5304.

22. Grode L, Seiler P, Baumann S, Hess J, Brinkmann V, Nasser EA, Mann P, Goosmann C, Bandermann S, Smith D, Bancroft GJ, Reyrat JM, van Soolingen D, Raupach B, Kaufmann SH (2005) Increased vaccine efficacy against tuberculosis of recombinant Mycobacterium bovis bacille Calmette-Guerin mutants that secrete listeriolysin. J Clin Invest 115: 2472-2479.

23. Grode L, Kursar M, Fensterle J, Kaufmann SH, and Hess J (2002) Cell-mediated immunity induced by recombinant Mycobacterium bovis Bacille Calmette-Guerin strains against an intracellular bacterial pathogen: importance of antigen secretion or membrane-targeted antigen display as lipoprotein for vaccine efficacy. J Immunol 168: 1869-1876.

24. Kaufmann SH and Gengenbacher M (2012) Recombinant live vaccine candidates against tuberculosis. Curr Opin Biotechnol 23: 900-907

25. Sun R, Skeiky YA, Izzo A, Dheenadhayalan V, Imam Z, Penn E, Stagliano K, Haddock S, Mueller S, Fulkerson J, Scanga G, Grover A, Derrick SC, Morris S, Hone DM, Horwitz MA, Kaufmann SH, Sadoff JC (2009) Novel recombinant BCG expressing perfringolysin $\mathrm{O}$ and the over-expression of key immunodominant antigens; pre-clinical characterization, safety and protection against challenge with Mycobacterium tuberculosis. Vaccine 27: 4412-4423.

26. Russell DG (2007) Who puts the tubercle in tuberculosis? Nat Rev Microbiol 5: 39-47.

27. Kaufmann SH, Cole ST, Mizrahi V, Rubin E, and Nathan C (2005) Mycobacterium tuberculosis and the host response. $\mathrm{J}$ Exp Med 201: 1693-1697.

28. Flynn JL and Chan J (2005) What's good for the host is good for the bug. Trends Microbiol 13: 98-102.

29. Abdallah AM, Gey van Pittius NC, Champion PA, Cox J, Luirink J, Vandenbroucke-Grauls CM, Appelmelk BJ, and Bitter W (2007) Type VII secretion--mycobacteria show the way. Nat Rev Microbiol 5: 883-891.

30. Stoop EJ, Bitter W, and van der Sar AM (2012) Tubercle bacilli rely on a type VII army for pathogenicity. Trends Microbiol 20: 477-484.

31. Sutcliffe IC and Harrington DJ (2004) Lipoproteins of Mycobacterium tuberculosis: an abundant and functionally diverse class of cell envelope components. FEMS Microbiol Rev 28: 645-659.

32. Cole ST, Brosch R, Parkhill J, Garnier T, Churcher C, Harris D, Gordon SV, Eiglmeier K, Gas S, Barry CE, III, Tekaia F, Badcock K, Basham D, Brown D, Chillingworth T, Connor R, Davies R, Devlin K, Feltwell T, Gentles S, Hamlin N, Holroyd S, Hornsby T, Jagels K, Krogh A, McLean J, Moule S, Murphy L, Oliver K, Osborne J, Quail MA, Rajandream MA, Rogers J, Rutter S, Seeger K, Skelton J, Squares R, Sulston JE, Taylor K, Whitehead S, Barrell BG (1998) Deciphering the biology of Mycobacterium tuberculosis from the complete genome sequence [see comments] [published erratum appears in Nature 1998 Nov 12;396(6707):190] Nature 393: 537-544.
33. Wilkinson KA, Newton SM, Stewart GR, Martineau AR, Patel J, Sullivan SM, Herrmann JL, Neyrolles O, Young DB, and Wilkinson RJ (2009) Genetic determination of the effect of post-translational modification on the innate immune response to the $19 \mathrm{kDa}$ lipoprotein of Mycobacterium tuberculosis. BMC Microbiol 9: 93.

34. Booth RJ, Williams DL, Moudgil KD, Noonan LC, Grandison PM, McKee JJ, Prestidge RL, and Watson JD (1993) Homologs of Mycobacterium leprae 18-kilodalton and Mycobacterium tuberculosis 19-kilodalton antigens in other mycobacteria. Infect Immun 61: 1509-1515.

35. Brightbill HD, Libraty DH, Krutzik SR, Yang RB, Belisle JT, Bleharski JR, Maitland M, Norgard MV, Plevy SE, Smale ST, Brennan PJ, Bloom BR, Godowski PJ, Modlin RL (1999) Host defense mechanisms triggered by microbial lipoproteins through toll-like receptors. Science 285: 732-736.

36. Pai RK, Convery M, Hamilton TA, Boom WH, and Harding CV (2003) Inhibition of IFN-gamma-induced class II transactivator expression by a $19-\mathrm{kDa}$ lipoprotein from Mycobacterium tuberculosis: a potential mechanism for immune evasion. J Immunol 171: 175-184.

37. Lopez M, Sly LM, Luu Y, Young D, Cooper H, and Reiner NE (2003) The 19-kDa Mycobacterium tuberculosis protein induces macrophage apoptosis through Toll-like receptor-2. J Immunol 170: 2409-2416

38. Ciaramella A, Cavone A, Santucci MB, Garg SK, Sanarico N, Bocchino M, Galati D, Martino A, Auricchio G, D'Orazio M, Stewart GR, Neyrolles O, Young DB, Colizzi V, Fraziano M (2004) Induction of apoptosis and release of interleukin-1 beta by cell wall-associated $19-\mathrm{kDa}$ lipoprotein during the course of mycobacterial infection. J Infect Dis 190: 1167-1176.

39. Behar SM, Martin CJ, Booty MG, Nishimura T, Zhao X, Gan HX, Divangahi M, and Remold HG (2011) Apoptosis is an innate defense function of macrophages against Mycobacterium tuberculosis. Mucosal Immunol 4: 279-287.

40. Yeremeev VV, Lyadova IV, Nikonenko BV, Apt AS, AbouZeid C, Inwald J, and Young DB (2000) The 19-kD antigen and protective immunity in a murine model of tuberculosis [In Process Citation]. Clin Exp Immunol 120: 274-279.

41. Yeremeev VV, Stewart GR, Neyrolles O, Skrabal K, Avdienko VG, Apt AS, and Young DB (2000) Deletion of the $19 \mathrm{kDa}$ antigen does not alter the protective efficacy of BCG. Tuber Lung Dis 80: 243-247.

42. Henao-Tamayo M, Junqueira-Kipnis AP, Ordway D, Gonzales-Juarrero M, Stewart GR, Young DB, Wilkinson RJ, Basaraba RJ, and Orme IM (2007) A mutant of Mycobacterium tuberculosis lacking the 19-kDa lipoprotein Rv3763 is highly attenuated in vivo but retains potent vaccinogenic properties. Vaccine 25: 7153-7159.

43. Santucci MB, Amicosante M, Cicconi R, Montesano C, Casarini M, Giosue S, Bisetti A, Colizzi V, and Fraziano M (2000) Mycobacterium tuberculosis-induced apoptosis in monocytes/macrophages: early membrane modifications and intracellular mycobacterial viability. J Infect Dis 181: 15061509.

44. Menozzi FD, Rouse JH, Alavi M, Laude-Sharp M, Muller J, Bischoff R, Brennan M., and Locht C (1996) Identification of a heparin-binding hemagglutinin present in mycobacteria. $\mathrm{J}$ Exp Med 184: 993-1001.

45. Pethe K, Alonso S, Biet F, Delogu G, Brennan MJ, Locht C, and Menozzi FD (2001) The heparin-binding haemagglutinin of $M$. tuberculosis is required for extrapulmonary dissemination. Nature 412: 190-194. 
46. Menozzi FD, Bischoff R, Fort E, Brennan MJ, and Locht C (1998) Molecular characterization of the mycobacterial heparin-binding hemagglutinin, a mycobacterial adhesin. Proc Natl Acad Sci USA 95: 12625-12630.

47. Delogu G and Brennan MJ (1999) Functional domains present in the mycobacterial hemagglutinin, HBHA. J Bacteriol 181: 7464-7469.

48. Esposito C, Marasco D, Delogu G, Pedone E, and Berisio R (2011) Heparin-binding hemagglutinin HBHA from Mycobacterium tuberculosis affects actin polymerisation. Biochem Biophys Res Commun 410: 339-344.

49. Delogu G, Fadda G, and Brennan MJ (2012) Impact of Structural Domains of the Heparin Binding Hemagglutinin of Mycobacterium tuberculosis on Function. Protein Pept Lett 19: $1035-1039$.

50. Dupres V, Menozzi FD, Locht C, Clare BH, Abbott NL, Cuenot S, Bompard C, Raze D, and Dufrene YF (2005) Nanoscale mapping and functional analysis of individual adhesins on living bacteria. Nature Methods 2: 515-520.

51. Li Z, Howard A, Kelley C, Delogu G, Collins F, and Morris S (1999) Immunogenicity of DNA vaccines expressing tuberculosis proteins fused to tissue plasminogen activator signal sequences [In Process Citation]. Infect Immun 67: 4780-4786.

52. Masungi C, Temmerman S, Van Vooren JP, Drowart A, Pethe K, Menozzi FD, Locht C, and Mascart F (2002) Differential T and B cell responses against Mycobacterium tuberculosis heparin-binding hemagglutinin adhesin in infected healthy individuals and patients with tuberculosis. J Infect Dis 185: 513-520.

53. Zanetti S, Bua A, Delogu G, Pusceddu C, Mura M, Saba F, Pirina P, Garzelli C, Vertuccio C, Sechi LA, and Fadda G (2005) Patients with pulmonary tuberculosis develop a strong humoral response against methylated heparin-binding hemagglutinin. Clin Diagn Lab Immunol 12: 1135-1138.

54. Temmerman S, Pethe K, Parra M, Alonso S, Rouanet C, Pickett T, Drowart A, Debrie AS, Delogu G, Menozzi FD, Sergheraert C, Brennan MJ, Mascart F, and Locht C (2004) Methylation-dependent $\mathrm{T}$ cell immunity to Mycobacterium tuberculosis heparin-binding hemagglutinin. Nat Med 10: 935-941.

55. Parra M, Pickett T, Delogu G, Dheenadhayalan V, Debrie AS, Locht C, and Brennan MJ (2004). The Mycobacterial Heparin-binding Hemagglutinin is a Protective antigen in the Mouse Aerosol Challenge Model of Tuberculosis. Infect Immun 72: 6799-6805.

56. Hougardy JM, Schepers K, Place S, Drowart A, Lechevin V, Verscheure V, Debrie AS, Doherty TM, Van Vooren JP, Locht C, Mascart F (2007) Heparin-Binding-HemagglutininInduced IFN-gamma release as a diagnostic tool for latent tuberculosis. PLoS ONE 2: e926.

57. Place S, Verscheure V, de SN, Hougardy JM, Schepers K, Dirix V, Dediste A, Michel O, Drowart A, Allard SD, Doherty TM, Lecher S, Locht C, Mascart F (2010) Heparinbinding, hemagglutinin-specific IFN-gamma synthesis at the site of infection during active tuberculosis in humans. Am J Respir Crit Care Med 182: 848-854.

58. Shin AR, Lee KS, Lee JS, Kim SY, Song CH, Jung SB, Yang CS, Jo EK, Park JK, Paik TH, Kim HJ (2006) Mycobacterium tuberculosis HBHA protein reacts strongly with the serum immunoglobulin $\mathrm{M}$ of tuberculosis patients. Clin Vaccine Immunol 13: 869-875.
59. Delogu G, Chiacchio T, Vanini V, Butera O, Cuzzi G, Bua A, Molicotti P, Zanetti S, Lauria FN, Grisetti S, Magnavita N, Fadda G, Girardi E, and Goletti D (2011) Methylated HBHA produced in M. smegmatis Discriminates between Active and Non-Active Tuberculosis Disease among RD1-Responders. PLoS ONE 6: e1815.

60. Molicotti P, Bua A, Cubeddu M, Cannas S, Delogu G, and Zanetti S (2011) Tuberculosis patients are characterized by a low-IFN-gamma/high-TNF-alpha response to methylated HBHA produced in M. smegmatis. Diagn Microbiol Infect Dis 71: 449-452.

61. Corbiere V, Pottier G, Bonkain F, Schepers K, Verscheure V, Lecher S, Doherty TM, Locht C, and Mascart F (2012) Risk stratification of latent tuberculosis defined by combined interferon gamma release assays. PLoS ONE 7: e43285.

62. Temmerman ST, Place S, Debrie AS, Locht C, and Mascart F (2005) Effector functions of heparin-binding hemagglutininspecific CD8+ T lymphocytes in latent human tuberculosis. J Infect Dis 192: 226-232.

63. Kohama H, Umemura M, Okamoto Y, Yahagi A, Goga H, Harakuni T, Matsuzaki G, and Arakawa T (2008) Mucosal immunization with recombinant heparin-binding haemagglutinin adhesin suppresses extrapulmonary dissemination of Mycobacterium bovis bacillus CalmetteGuerin (BCG) in infected mice. Vaccine 26: 924-932.

64. Zhao S, Zhao Y, Mao F, Zhang C, Bai B, Zhang H, Shi C, and $\mathrm{Xu} \mathrm{Z}$ (2012) Protective and therapeutic efficacy of Mycobacterium smegmatis expressing HBHA-hIL12 fusion protein against Mycobacterium tuberculosis in mice. PLoS ONE 7: e31908.

65. Balasubramanian V, Wiegeshaus EH, Taylor BT, and Smith DW (1994) Pathogenesis of tuberculosis: pathway to apical localization. Tuber Lung Dis 75: 168-178.

66. Bottai D, Di LM, Majlessi L, Frigui W, Simeone R, Sayes F, Bitter W, Brennan MJ, Leclerc C, Batoni G, Campa M, Brosch R, Esin S (2012). Disruption of the ESX-5 system of Mycobacterium tuberculosis causes loss of PPE protein secretion, reduction of cell wall integrity and strong attenuation. Mol Microbiol 83: 1195-1209

67. Gey van Pittius NC, Sampson SL, Lee H, Kim Y, van Helden PD, and Warren RM (2006) Evolution and expansion of the Mycobacterium tuberculosis PE and PPE multigene families and their association with the duplication of the ESAT-6 (esx) gene cluster regions. BMC Evol Biol 6: 95.

68. Gey van Pittius NC, Gamieldien J, Hide W, Brown GD, Siezen RJ, and Beyers AD (2001) The ESAT-6 gene cluster of Mycobacterium tuberculosis and other high $\mathrm{G}+\mathrm{C}$ Grampositive bacteria. Genome Biol 2: RESEARCH0044

69. Gordon SV, Eiglmeier K, Garnier T, Brosch R, Parkhill J, Barrell B, Cole ST, and Hewinson RG (2001) Genomics of Mycobacterium bovis. Tuberculosis (Edinb) 81: 157-163.

70. Pym AS, Brodin P, Brosch R, Huerre M, and Cole ST (2002) Loss of RD1 contributed to the attenuation of the live tuberculosis vaccines Mycobacterium bovis BCG and Mycobacterium microti. Mol Microbiol 46: 709-717.

71. Diel R, Goletti D, Ferrara G, Bothamley G, Cirillo D, Kampmann B, Lange C, Losi M, Markova R, Migliori GB, Nienhaus A, Ruhwald M, Wagner D, Zellweger JP, Huitric E, Sandgren A, Manissero D, (2011) Interferon-gamma release assays for the diagnosis of latent Mycobacterium tuberculosis infection: a systematic review and meta-analysis. Eur Respir J 37: 88-99. 
72. Hsu T, Hingley-Wilson SM, Chen M, Dai AZ, Morin PM, Marks CB, Padiyar J, Goulding C, Gingery M, Eisemberg D, Russell RG, Derrick SC, Collins FM, Morris SL, King CH, Jacobs WR, Jr (2003) The primary mechanism of attenuation of bacillus Calmette-Guerin is a loss of secreted lytic function required for invasion of lung interstitial tissue. Proc Natl Acad Sci USA 100: 12420-12425.

73. Frigui W, Bottai D, Majlessi L, Monot M, Josselin E, Brodin P, Garnier T, Gicquel B, Martin C, Leclerc C, Cole ST, Brosch R (2008) Control of M. tuberculosis ESAT-6 secretion and specific $\mathrm{T}$ cell recognition by PhoP. PLoS Pathog 4: e33.

74. Perez E, Samper S, Bordas Y, Guilhot C, Gicquel B, and Martin C (2001) An essential role for phoP in Mycobacterium tuberculosis virulence. Mol Microbiol 41: 179-187.

75. Gonzalo AJ, Maia C, Ferrer NL, Barilone N, Laval F, Soto CY, Winter N, Daffe M, Gicquel B, Martin C, Jackson M (2006) The virulence-associated two-component PhoP-PhoR system controls the biosynthesis of polyketide-derived lipids in Mycobacterium tuberculosis. J Biol Chem 281: 1313-1316.

76. Gonzalo-Asensio J, Mostowy S, Harders-Westerveen J, Huygen K, Hernandez-Pando R, Thole J, Behr M, Gicquel B, and Martin C (2008). PhoP: a missing piece in the intricate puzzle of Mycobacterium tuberculosis virulence. PLoS ONE 3: e3496.

77. Cardona PJ, Asensio JG, Arbues A, Otal I, Lafoz C, Gil O, Caceres N, Ausina V, Gicquel B, and Martin C (2009) Extended safety studies of the attenuated live tuberculosis vaccine SO2 based on phoP mutant. Vaccine 27: 2499-2505.

78. Siegrist MS, Unnikrishnan M, McConnell MJ, Borowsky M, Cheng TY, Siddiqi N, Fortune SM, Moody DB, and Rubin EJ (2009) Mycobacterial Esx-3 is required for mycobactinmediated iron acquisition. Proc Natl Acad Sci USA 106: 18792-18797.

79. Serafini A, Boldrin F, Palu G, and Manganelli R (2009) Characterization of a Mycobacterium tuberculosis ESX-3 conditional mutant: essentiality and rescue by iron and zinc. $\mathrm{J}$ Bacteriol 191: 6340-6344.

80. Maciag A, Dainese E, Rodriguez GM, Milano A, Provvedi R, Pasca MR, Smith I, Palu G, Riccardi G, and Manganelli R (2007) Global analysis of the Mycobacterium tuberculosis Zur (FurB) regulon. J Bacteriol 189: 730-740.

81. Sweeney KA, Dao DN, Goldberg MF, Hsu T, Venkataswamy MM, Henao-Tamayo M, Ordway D, Sellers RS, Jain P, Chen B, Chen M, Kim J, Lukose R, Chan J, Orme IM, Porcelli SA, Jacobs WR, Jr (2011) A recombinant Mycobacterium smegmatis induces potent bactericidal immunity against Mycobacterium tuberculosis. Nat Med 17: 1261-1268.

82. Abdallah AM, Savage ND, van ZM, Wilson L, Vandenbroucke-Grauls CM, van der Wel NN, Ottenhoff TH, and Bitter W (2008) The ESX-5 secretion system of Mycobacterium marinum modulates the macrophage response. J Immunol 181: 7166-7175.

83. Sayes F, Sun L, Di Luca M, Simeone R, Degaiffier N, Fiette L, Esin S, Brosch R, Bottai D, Leclerc C, Majlessi L (2012) Strong immunogenicity and cross-reactivity of Mycobacterium tuberculosis ESX-5 type VII secretion: encoded PE-PPE proteins predicts vaccine potential. Cell Host Microbe 11: 352-363.

84. Rodrigue S, Provvedi R, Jacques PE, Gaudreau L, and Manganelli R (2006) The sigma factors of Mycobacterium tuberculosis. FEMS Microbiol Rev 30: 926-941.
85. Manganelli R, Voskuil MI, Schoolnik GK, and Smith I (2001) The Mycobacterium tuberculosis ECF sigma factor sigmaE: role in global gene expression and survival in macrophages. Mol Microbiol 41: 423-437.

86. Manganelli R, Provvedi R, Rodrigue S, Beaucher J, Gaudreau L, and Smith I (2004) Sigma factors and global gene regulation in Mycobacterium tuberculosis. J Bacteriol 186: 895-902.

87. Hernandez PR, Aguilar LD, Smith I, and Manganelli R (2010) Immunogenicity and protection induced by a Mycobacterium tuberculosis sigE mutant in a BALB/c mouse model of progressive pulmonary tuberculosis. Infect Immun 78: 3168-3176.

88. Brennan MJ and Delogu G (2002). The PE multigene family: a 'molecular mantra' for mycobacteria. Trends Microbiol 10: 246-249.

89. Strong M, Sawaya MR, Wang S, Phillips M, Cascio D, and Eisenberg D (2006) Toward the structural genomics of complexes: crystal structure of a PE/PPE protein complex from Mycobacterium tuberculosis. Proc Natl Acad Sci USA 103: 8060-8065.

90. Adindla S and Guruprasad L (2003) Sequence analysis corresponding to the PPE and PE proteins in Mycobacterium tuberculosis and other genomes. J Biosci 28: 169-179.

91. Daleke $\mathrm{MH}$, Cascioferro A, de Punder K, Ummels R, Abdallah AM, van der WN, Peters PJ, Luirink J, Manganelli $\mathrm{R}$, and Bitter W (2011) Conserved PE and PPE protein domains target LipY lipases of pathogenic mycobacteria to the cell surface via ESX-5. J Biol Chem 286: 19024-19034

92. Mishra KC, de CC, Narayana Y, Bifani P, Brown AK, Besra GS, Katoch VM, Joshi B, Balaji KN, and Kremer L (2008) Functional role of the PE domain and immunogenicity of the Mycobacterium tuberculosis triacylglycerol hydrolase LipY. Infect Immun 76: 127-140.

93. Brennan MJ, Delogu G, Chen Y, Bardarov S, Kriakov J, Alavi M, and Jacobs WR, Jr (2001) Evidence that mycobacterial PE_PGRS proteins are cell surface constituents that influence interactions with other cells. Infect Immun 69: 7326-7333.

94. Banu S, Honore N, Saint-Joanis B, Philpott D, Prevost MC, and Cole ST (2002) Are the PE-PGRS proteins of Mycobacterium tuberculosis variable surface antigens? Mol Microbiol 44: 9-19.

95. Delogu G, Pusceddu C, Bua A, Fadda G, Brennan MJ, and Zanetti S (2004) Rv1818c-encoded PE_PGRS protein of Mycobacterium tuberculosis is surface exposed and influences bacterial cell structure. Mol Microbiol 52: 725733.

96. Cascioferro A, Delogu G, Colone M, Sali M, Stringaro A, Arancia G, Fadda G, Palu G, and Manganelli R (2007) PE is a functional domain responsible for protein translocation and localization on mycobacterial cell wall. Mol Microbiol 66: 1536-1547.

97. Hoffmann C, Leis A, Niederweis M, Plitzko JM, and Engelhardt H (2008) Disclosure of the mycobacterial outer membrane: cryo-electron tomography and vitreous sections reveal the lipid bilayer structure. Proc Natl Acad Sci USA 105: 3963-3967.

98. Zuber B, Chami M, Houssin C, Dubochet J, Griffiths G, and Daffe M (2008) Direct visualization of the outer membrane of mycobacteria and corynebacteria in their native state. J Bacteriol 190: 5672-5680. 
99. Sali M, Di Sante G, Cascioferro A, Zumbo A, Nicolo C, Dona V, Rocca S, Procoli A, Morandi M, Ria F, Palù G, Fadda G, Manganelli R, Delogu G (2010) Surface expression of MPT64 as a fusion with the PE domain of PE PGRS33 enhances Mycobacterium bovis BCG protective activity against Mycobacterium tuberculosis in mice. Infect Immun 78: 5202-5213.

100. Andersen P and Doherty TM (2005) The success and failure of BCG - implications for a novel tuberculosis vaccine. Nat Rev Microbiol 3: 656-662.

\section{Corresponding author}

Prof. Giovanni Delogu

Istituto di Microbiologia

Università Cattolica del Sacro Cuore Roma

Largo A. Gemelli, 8 - 00168 - Rome, Italy

Telephone: ++390630154964 ; fax ++39063051152

Email: gdelogu@rm.unicatt.it

Conflict of interests: No conflict of interests is declared. 